\title{
HYPONORMAL TOEPLITZ OPERATORS ON THE BERGMAN SPACE
}

\author{
Houcine SADRAOUi AND MOHAMEd Guediri
}

\begin{abstract}
A Hilbert space operator is hyponormal if $T^{*} T-T T^{*}$ is positive. We consider hyponormality of Toeplitz operators on the Bergman space with a symbol in the class of $f+\bar{g}$ where $f$ is a monomial and $g$ is a polynomial. We give sufficient conditions for hyponormality in this case.

Mathematics subject classification (2010): Primary 47B35, 47B20, Secondary $15 \mathrm{~B} 48$.

Keywords and phrases: Toeplitz operator, hyponormal, positive matrix.
\end{abstract}

\section{REFERENCES}

[1] P. AHERn AND Z. CUCKOviC, A mean value inequality with applications to Bergman space operators, Pac. J. Math, vol. 173, no. 2 (1996), 295-305.

[2] S. AXLER, Bergman spaces and their operators, in Surveys of Some Recent results in Operator Theory, vol. 1, Pitman Research Notes in Math, vol. 171, Longman, Harlow, 1988, pp. 1-50.

[3] S. AXLER, Bergman space, the Bloch space and commutators of multiplication operators, Duke Math. J. 53 (1986), pp. 315-332.

[4] J. Conway, Subnormal Operators, Pitman, Boston, 1981.

[5] C. Cowen, Hyponormal and subnormal Toeplitz operators, in Surveys of Some Results in Operator Theory, vol. 1, Pitman Research Notes in Math, vol. 171, Longman, Harlow, 1988, pp. 155-167.

[6] C. Cowen, Hyponormality of Toeplitz operatos, Proc. Amer. Math. Soc. 103 (1988), pp. 809-812.

[7] C. CowEN, An application of Hadamard multiplication to operators on weighted Hardy spaces, Linear Alg. Appl. 133 (1990), pp. 21-32.

[8] R. Douglas, Banach Algebra Techniques in Operator Theory, Academic Press, New York, 1972.

[9] R. Douglas, On majorization, factorization, and range inclusion of operators on Hilbert space, Proc. Amer. Math. Soc. 17 (1966), pp. 21-32.

[10] P. Duren, Theory of $H^{p}$ spaces, Academic press, New York, 1970.

[11] H. Dym And I. Gohberg, Extensions of band matrices with band inverses, Linear. Alg. Appl. 36 (1981), pp. 1-24.

[12] U. Grenander And G. Szego, Toeplitz Forms and Their Applications, University of California Press, Berkeley and Los Angeles, 1958.

[13] R. Horn And C. Johnson, Matrix Analysis, Cambridge University Press, Cambridge, 1985.

[14] V. Paulsen,, Completely Bouded Maps and Dilations, Pitman Research Notes in Math, vol. 146, Wiley, New York, 1986.

[15] H. SADRAOUI, Hyponormality of Toeplitz operators and composition operators, Thesis, Purdue University, 1992.

[16] K. ZHU, Operator Theory in Function Spaces, Dekker, New York, 1990. 